\title{
Article
}

\section{Zn Promoted Mg-Al Mixed Oxides-Supported Gold Nanoclusters for Direct Oxidative Esterification of Aldehyde to Ester}

\author{
Jie Li ${ }^{1}$, Shiyi Wang ${ }^{1}$, Huayin $\mathrm{Li}^{1}$, Yuan Tan ${ }^{1, *}$ and Yunjie Ding ${ }^{1,2,3, *}$ \\ 1 Hangzhou Institute of Advanced Studies, Zhejiang Normal University, 1108 Gengwen Road, \\ Hangzhou 311231, China; lijie_zjnu@163.com (J.L.); wangshiyi@dicp.ac.cn (S.W.); \\ lihuayin@zjnu.edu.cn (H.L.) \\ 2 Dalian National Laboratory for Clean Energy, Dalian Institute of Chemical Physics, \\ Chinese Academy of Sciences, Dalian 116023, China \\ 3 The State Key Laboratory of Catalysis, Dalian Institute of Chemical Physics, Chinese Academy of Sciences, \\ Dalian 116023, China \\ * Correspondence: yuantan2012@zjnu.edu.cn (Y.T.); dyj@dicp.ac.cn (Y.D.); Tel.: +86-571-82257902 (Y.T.); \\ +86-411-84379143 (Y.D.)
}

check for updates

Citation: Li, J.; Wang, S.; Li, H.; Tan, Y.; Ding, Y. Zn Promoted Mg-Al Mixed Oxides-Supported Gold Nanoclusters for Direct Oxidative Esterification of Aldehyde to Ester. Int. J. Mol. Sci. 2021, 22, 8668. https://doi.org/10.3390/ ijms22168668

Academic Editor: Raghvendra Singh Yadav

Received: 30 June 2021

Accepted: 10 August 2021

Published: 12 August 2021

Publisher's Note: MDPI stays neutral with regard to jurisdictional claims in published maps and institutional affiliations.

Copyright: (c) 2021 by the authors. Licensee MDPI, Basel, Switzerland. This article is an open access article distributed under the terms and conditions of the Creative Commons Attribution (CC BY) license (https:/ creativecommons.org/licenses/by/ $4.0 /)$.

\begin{abstract}
The synthesis of ester compounds is one of the most important chemical processes. In this work, $\mathrm{Zn}-\mathrm{Mg}-\mathrm{Al}$ mixed oxides with different $\mathrm{Zn}^{2+} / \mathrm{Mg}^{2+}$ molar ratios were prepared via coprecipitation method and supported gold nanoclusters to study the direct oxidative esterification of aldehyde and alcohol in the presence of molecular oxygen. Various characterization techniques such as $\mathrm{N}_{2}$-physical adsorption, $\mathrm{X}$-ray diffraction (XRD), transmission electron microscopy (TEM), $\mathrm{X}$-ray photoelectron spectroscopy (XPS) and $\mathrm{CO}_{2}$ temperature programmed desorption (TPD) were utilized to analyze the structural and electronic properties. Based on the results, the presence of small amounts of $\mathrm{Zn}^{2+}$ ions ( $\left.5 \mathrm{wt} . \%\right)$ provoked a remarkable modification of the binary $\mathrm{Mg}-\mathrm{Al}$ system, which enhanced the interaction between gold with the support and reduced the particle size of gold. For oxidative esterification reaction, the $\mathrm{Au}_{25} / \mathrm{Zn}_{0.05} \mathrm{MgAl}-400$ catalyst showed the best performance, with the highest turnover frequency (TOF) of $1933 \mathrm{~h}^{-1}$. The active center was believed to be located at the interface between metallic gold with the support, where basic sites contribute a lot to transformation of the substrate.
\end{abstract}

Keywords: gold catalyst; cluster; hydrotalcite; oxidative esterification; methyl isobutyrate

\section{Introduction}

Ester compounds are one of the most important raw materials in chemical industry and organic synthesis and constitute numerous artificial fragrances, flavoring agents, solvent extractants and chemical intermediates [1]. The traditional synthetic method for preparation of esters involves a two-step procedure, including the oxidation of aldehyde and/or alcohol and the subsequent esterification between carboxylic acid and its activated derivatives with alcohols [2-4]. The multistep process involves the production of large amounts of toxic wastes and irremovable byproducts, which is not conducive to the development of green chemistry. Therefore, the synthesis of esters through one-step oxidative esterification from aldehydes and alcohols has attracted great interest in recent years.

Traditionally, the direct oxidative esterification requires homogeneous stoichiometric reagents, such as $\mathrm{KMnO}_{4}$ [5], $\mathrm{CrO}_{3}$ [6], $\mathrm{H}_{2} \mathrm{O}_{2}$ [7], etc., while the strong oxidants not only call for harsh conditions but also cause separation difficulties. Therefore, the green oxidants such as air and dioxygen over heterogeneous catalysts under mild conditions are highly desirable. The supported noble metal Pd-based catalysts have been reported to be efficient for one-step oxidative cross-esterification reaction between aldehyde and 
alcohol in the presence of molecular oxygen [8-12]. However, the selectivity of the corresponding esters is typically low and this process requires the addition of environmentally unfriendly heavy metals, such as $\mathrm{Pb}$ and $\mathrm{Bi}$ [8-10]. Furthermore, the utilization of liquid base additives is needed for Pd-based catalysts, which makes the process less green and not cost-effective [11,12].

Supported gold catalysts are a great promising candidate for this kind of reaction due to their unique selectivity under mild conditions [13-18]. Various transition-metaloxides and mixed oxides were explored as supports for synthesis of the supported gold catalysts [15-18]. Nevertheless, their catalytic performances were largely dependent on the particle size of gold [15], the interaction between gold and the carrier [16], as well as the acidic-basic properties of the supports $[15,17]$. Thus, preparation of highly efficient gold catalysts for synthesis of the corresponding esters is always considered in combination of the size of gold and the properties of the supports.

$\mathrm{Mg}$-Al hydrotalcite (HT) is a common solid base with unique layered structure, which plays an important role in many base-catalyzed reactions, such as alcohol oxidation [19,20], aldol condensation [21] and transesterification [22]. Their catalytic performances can be modified by incorporating various metal ions, such as $\mathrm{Cu}^{2+}[23,24], \mathrm{Zn}^{2+}[25,26], \mathrm{Ni}^{2+}[27]$, $\mathrm{Y}^{3+}$ [28], $\mathrm{Zr}^{4+}$ [29], etc. For example, Pavel et al. [28] reported yttrium-modified Mg-Al-HTs for epoxidation of styrene with hydrogen peroxide. An increment in catalytic activity was observed with the addition of $\mathrm{Y}^{3+}$ cations, which increased the alkalinity of catalysts accordingly. Willinton et al. [25] prepared Mg-Zn-Al HTs and their derived mixed oxides for the aldol condensation reaction. They found the presence of $\mathrm{Zn}^{2+}$ ions caused a clear influence on the acidic-basic properties of the catalysts when compared to the binary $\mathrm{Mg}-\mathrm{Al}$ system, which influenced the activity and selectivity greatly.

Previously, our group reported that the Zn-Al HT-derived mixed oxides-supported gold catalysts were highly selective and resistant for high temperature sintering in hydrogenation reactions of functionalized nitroarenes due to the strong interaction between gold with the support [30]. Later, we found that the catalyst is also active and selective for synthesis of methyl methacrylate from methacrolein and methanol [31]. Herein, in this work, we try to incorporate $\mathrm{Zn}^{2+}$ ions into Mg-Al HTs for synthesis of stable gold catalysts for inorganic base-free oxidative esterification of aldehyde to ester. By adjusting the molar ratios of $\mathrm{Mg}^{2+} / \mathrm{Zn}^{2+}$ ions, the textural and electronic properties of supported gold catalysts were investigated in detail, in which $\mathrm{N}_{2}$ physical adsorption-desorption, $\mathrm{X}$-ray powder diffraction (XRD), transmission electron microscopy (TEM), X-ray photoelectron spectroscopy (XPS) and $\mathrm{CO}_{2}$ temperature programmed desorption (TPD) were successively explored. Based on these results, a clear insight into the structure-performance relationship over supported gold catalysts for direct oxidative esterification was provided.

\section{Results}

\subsection{Compositional and Textural Analysis of the Catalysts}

For synthesis of the $\mathrm{Zn}-\mathrm{Mg}$-Al mixed oxides-supported gold catalysts, $\mathrm{Au}_{25}$ nanoclusters were firstly prepared through the sol-gel method with cysteine as the protective ligand, defined by UV-visible spectra (Figure S1). Then, different supports with various molar ratios of $\mathrm{Zn}^{2+} / \mathrm{Mg}^{2+}$ were impregnated with the solution of $\mathrm{Au}_{25}$. Before each test, the samples were dried overnight and pretreated in muffle at $400{ }^{\circ} \mathrm{C}$ for $2 \mathrm{~h}$ to remove most of the protective ligands. After that, various characterizations of the structural and electronic properties of the catalysts were carried out under specific conditions. The actual metal loadings of gold were measured by inductively coupled plasma atomic emission spectroscopy (ICP-AES), from which all catalysts showed similar values of $~ 1.5 \mathrm{wt} . \%$ (Table 1), which agrees well with the nominal values. 
Table 1. Textural properties of $\mathrm{Zn}-\mathrm{Mg}-\mathrm{Al}$ mixed oxides-supported gold catalysts.

\begin{tabular}{|c|c|c|c|c|c|c|c|}
\hline Entry & Catalysts & $\begin{array}{l}\text { Loadings } \\
\text { of } \mathrm{Au} \mathrm{( \% )}{ }^{\mathrm{a}}\end{array}$ & $\begin{array}{c}S_{\text {BET }} \\
\left(m^{2} g^{-1}\right)^{b}\end{array}$ & $\begin{array}{c}\text { Volume } \\
\left(\mathrm{cm}^{3} \mathrm{~g}^{-1}\right)^{b}\end{array}$ & $D_{\text {pore }}(\mathrm{nm})^{b}$ & $\begin{array}{c}\text { Particle } \\
\text { Size }(\mathrm{nm})^{\mathrm{c}}\end{array}$ & $\begin{array}{l}\text { Total Basicity } \\
\left(\mu \mathrm{mol} \mathrm{g}^{-1}\right)^{\mathrm{d}}\end{array}$ \\
\hline 1 & $\mathrm{Au}_{25} / \mathrm{MgAl}-400$ & 1.52 & 221.1 & 0.51 & 0.57 & 2.6 & 158 \\
\hline 2 & $\mathrm{Au}_{25} / \mathrm{Zn}_{0.05} \mathrm{MgAl}-400$ & 1.52 & 242.0 & 0.51 & 0.57 & 1.8 & 111 \\
\hline 3 & $\mathrm{Au}_{25} / \mathrm{Zn}_{0.33} \mathrm{MgAl}-400$ & 1.52 & 132.4 & 0.37 & 0.56 & 1.9 & 81 \\
\hline 4 & $\mathrm{Au}_{25} / \mathrm{Zn}_{3} \mathrm{MgAl}-400$ & 1.47 & 113.9 & 0.35 & 0.56 & 1.9 & 23 \\
\hline 5 & $\mathrm{Au}_{25} / \mathrm{ZnAl}-400$ & 1.50 & 91.1 & 0.24 & 0.56 & 1.9 & 29 \\
\hline
\end{tabular}

${ }^{a}$ : The actual loadings of gold were evaluated by ICP-AES measurement. ${ }^{b}:$ Specific surface area $\left(\mathrm{S}_{\mathrm{BET}}\right)$, total pore volume and average pore size were calculated from $\mathrm{N}_{2}$ physical adsorption-desorption. $\mathrm{S}_{\mathrm{BET}}$ were calculated from BET equation at $\mathrm{P} / \mathrm{P}_{0}$ range of $0.05-0.3$. Total pore volumes were calculated at $\mathrm{P} / \mathrm{P}_{0}=0.98$. Pore sizes were calculated from the adsorption branch of the isotherm-BJH. ${ }^{c}$ : The mean particle sizes were calculated from TEM measurement. ${ }^{\mathrm{d}}$ : Total basicity was calculated from $\mathrm{CO}_{2}-\mathrm{TPD}$ experiments.

The specific surface area, pore width and pore volume were measured by a nitrogen adsorption-desorption test. The isothermal curves and contrastive results are shown in Figure 1 and Table 1. In Figure 1a, Zn-Mg-Al mixed oxides-supported gold catalysts present typically type IV isotherms according to the IUPAC classification [32]. Furthermore, the hysteresis loops are $\mathrm{H} 3$ type and are located at higher relative pressures, indicating the formation of slit-shaped holes and the presence of mesopores, which were derived from the collapse of hydrotalcite structure after calcination [33]. To be noted, with the increase of $\mathrm{Zn}^{2+}$ ions into the $\mathrm{Mg}-\mathrm{Al}$ mixed oxides, the pore volumes and pore sizes of catalysts declined, while the surface area of catalysts increased initially from 221.1 to $242.0 \mathrm{~m}^{2} / \mathrm{g}$ and then decreased drastically to about $100 \mathrm{~m}^{2} / \mathrm{g}$. This is likely derived from the variation of phase structure of catalysts and it implies that the structural property of catalysts could be adjusted by the addition of $\mathrm{Zn}^{2+}$ ions. Later, the structural features were further analyzed by the following XRD results.
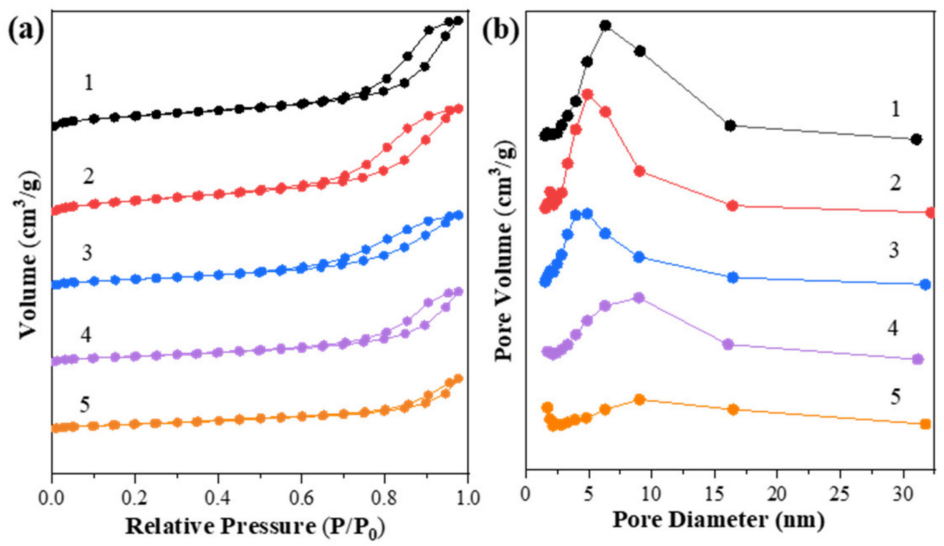

Figure 1. (a) $\mathrm{N}_{2}$ physical adsorption-desorption isotherms and (b) BJH-pore size distributions of Zn-Mg-Al mixed oxides-supported gold catalysts: (1) $\mathrm{Au}_{25} / \mathrm{MgAl}-400$; (2) $\mathrm{Au}_{25} / \mathrm{Zn}_{0.05} \mathrm{MgAl}-400$; (3) $\mathrm{Au}_{25} / \mathrm{Zn}_{0.33} \mathrm{MgAl}-400$; (4) $\mathrm{Au}_{25} / \mathrm{Zn}_{3} \mathrm{MgAl}-400$; (5) $\mathrm{Au}_{25} / \mathrm{ZnAl}-400$.

\subsection{Structural Analysis of the Catalysts}

The phase structure of Zn-modified Mg-Al-HT supported gold catalysts before and after thermal treatment was analyzed by X-ray diffraction (XRD). Figures 2 and 3 display the sample diffraction peaks. Before calcination, all samples exhibited layered characteristics of hydrotalcites, with sharp and intense lines located at $11.3^{\circ}, 22.8^{\circ}, 34.7^{\circ}, 39.1^{\circ}, 46.4^{\circ}$, $60.6^{\circ}$ and $61.9^{\circ}$ (Figure 2), corresponding to the (003), (006), (012), (015), (018), (110) and (113) planes (standard magnesium aluminum hydrotalcite JCPD NO. 00-035-0965, standard zinc aluminum hydrotalcite JCPD NO. 00-048-1023), respectively. The XRD patterns of the samples with fewer $\mathrm{Zn}^{2+}$ ions have broader reflections, which are close to that of the $\mathrm{Au}_{25} / \mathrm{MgAl}-\mathrm{HT}$ (Figure 2a), while the samples with more $\mathrm{Zn}^{2+}$ content present sharper reflections that are similar to the $\mathrm{Au}_{25} / \mathrm{ZnAl}-\mathrm{HT}$ (Figure 2e). 


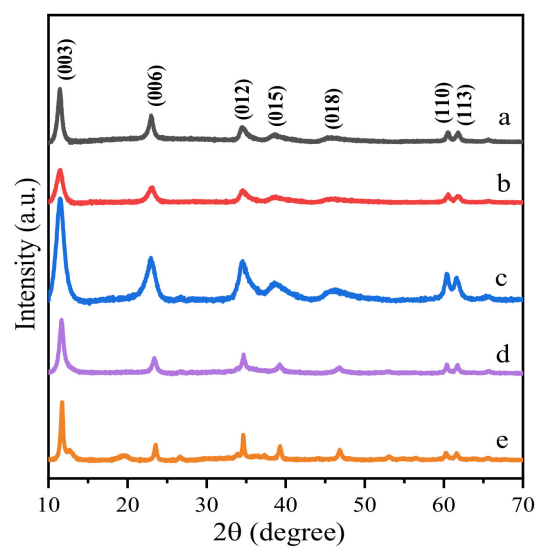

Figure 2. XRD spectra of $\mathrm{Zn}-\mathrm{Mg}-\mathrm{Al} \mathrm{HT}$ supported gold nanoclusters: (a) $\mathrm{Au}_{25} / \mathrm{MgAl}-\mathrm{HT}$; (b) $\mathrm{Au}_{25} / \mathrm{Zn}_{0.05} \mathrm{MgAl}-\mathrm{HT}$; (c) $\mathrm{Au}_{25} / \mathrm{Zn}_{0.33} \mathrm{MgAl}-\mathrm{HT}$; (d) $\mathrm{Au}_{25} / \mathrm{Zn}_{3} \mathrm{MgAl}-\mathrm{HT}$; (e) $\mathrm{Au}_{25} / \mathrm{ZnAl}-\mathrm{HT}$.

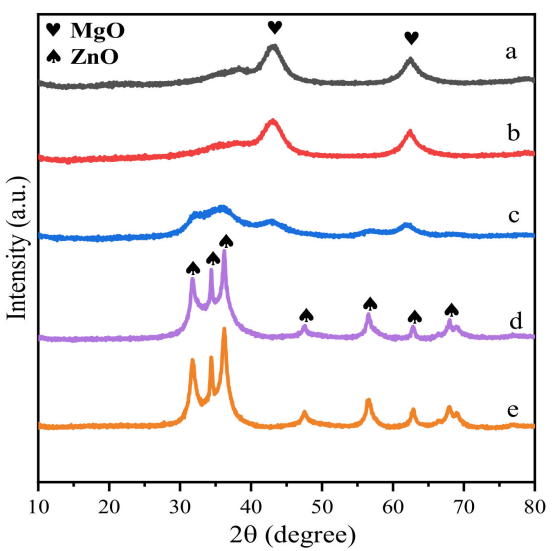

Figure 3. XRD spectra of $\mathrm{Zn}-\mathrm{Mg}-\mathrm{Al}$ mixed oxides-supported gold catalysts: (a) $\mathrm{Au}_{25} / \mathrm{MgAl}-400$; (b) $\mathrm{Au}_{25} / \mathrm{Zn}_{0.05} \mathrm{MgAl}-400$; (c) $\mathrm{Au}_{25} / \mathrm{Zn}_{0.33} \mathrm{MgAl}-400$; (d) $\mathrm{Au}_{25} / \mathrm{Zn}_{3} \mathrm{MgAl}-400$; (e) $\mathrm{Au}_{25} / \mathrm{ZnAl}-400$.

According to the literature, characteristics of (003) and (110) reflections correspond to basal and in-plane spacing [33,34]. Here, the lattice parameters (a and c) in Table 2 were calculated on the basis of a rhombohedral R3m space group and hexagonal cell by the formula of $a=2 d_{110}$ and $c=3 d_{003}[33,34]$. The parameter a represents the average distance between metal and metal in each layer of the hydrotalcite, whereas the parameter $\mathrm{c}$ reveals the distance between layer and layer [33]. From the results, the value of a remains constant upon zinc addition, while the value of c gradually decreases with increasing of $\mathrm{Zn}^{2+}$. This may be due to the similar ionic radius of octahedral coordinated $\mathrm{Mg}^{2+}(0.72 \AA)$ with $\mathrm{Zn}^{2+}(0.74 \AA)$ [35]. Hence, the effect of $\mathrm{Zn}$ substitution on the value of a was negligible. However, the larger electronegativity of $\mathrm{Zn}$ (1.66) compared to $\mathrm{Mg}$ (1.29) would lead to an increase in layer charge density, which is directly related to the decrease of interlayer distance [36]. Table 2 presents the crystal sizes of different samples that were calculated using Scherrer's equation. The increased crystallite sizes were consistent with the textural analysis. That is, a higher degree of crystallinity suggests a loss in surface area [36].

Furthermore, the XRD patterns of calcined samples after heat treatment at $400{ }^{\circ} \mathrm{C}$ are displayed in Figure 3. It can be clearly seen that the crystal structure of the samples exhibits typical periclase phase of $\mathrm{MgO}$ and/or zincite phase of $\mathrm{ZnO}$, with diffraction peaks at $37.0^{\circ}, 43.0^{\circ}, 62.3^{\circ}$ (JCPD 01-077-2364) and $31.8^{\circ}, 34.4^{\circ}, 36.3^{\circ}, 47.6^{\circ}, 56.6^{\circ}, 62.9^{\circ}, 68.0^{\circ}$ (JCPD 01-089-0510), respectively. When $5 \mathrm{wt} . \%$ of $\mathrm{Mg}^{2+}$ cations were substituted by $\mathrm{Zn}^{2+}$ ions $\left(\mathrm{Au}_{25} / \mathrm{Zn}_{0.05} \mathrm{MgAl}-400\right.$, Figure $\left.3 \mathrm{~b}\right)$, the structure of the catalyst was quite similar to the binary $\mathrm{Au}_{25} / \mathrm{MgAl}-400$. When the replacement increased to $35.6 \mathrm{wt} . \%\left(\mathrm{Au}_{25} / \mathrm{Zn}_{0.33} \mathrm{MgAl}-\right.$ 400, Figure 3c), both $\mathrm{MgO}$ and $\mathrm{ZnO}$ phase appears in the patterns. Further increasing the replacement of $\mathrm{Zn}^{2+}$ to $70.9 \mathrm{wt} . \%$ ( $\mathrm{Au}_{25} / \mathrm{Zn}_{3} \mathrm{MgAl}-400$, Figure $3 \mathrm{~d}$ ), the phase of $\mathrm{ZnO}$ 
dominates the structure. It implies that the addition of $\mathrm{Zn}^{2+}$ ions strongly affected the ordered structure of catalysts. In addition, no diffraction peaks attributed to face-centered cubic gold were observed in all heat-treated samples, indicating that the gold particles were highly dispersed and not aggregated under high temperature calcination.

Table 2. Crystallographic parameters calculated for Zn-Mg-Al HTs supported gold nanoclusters.

\begin{tabular}{|c|c|c|c|c|c|c|c|}
\hline \multirow{2}{*}{ Entry } & \multirow{2}{*}{ Catalysts } & \multirow{2}{*}{$d_{(003)}(n m)$} & \multirow{2}{*}{$d_{(110)}(n m)$} & \multirow{2}{*}{$\begin{array}{c}a \\
(\mathrm{~nm})^{a}\end{array}$} & \multirow{2}{*}{$\begin{array}{c}c \\
(\mathbf{n m})^{b}\end{array}$} & \multicolumn{2}{|c|}{ Crystallite Size $(\mathrm{nm})^{c}$} \\
\hline & & & & & & $(003)$ & (110) \\
\hline 1 & $\mathrm{Au}_{25} / \mathrm{MgAl}-400$ & 0.772 & 0.153 & 0.306 & 2.316 & 18 & 26 \\
\hline 2 & $\mathrm{Au}_{25} / \mathrm{Zn}_{0.05} \mathrm{MgAl}-400$ & 0.769 & 0.153 & 0.306 & 2.307 & 11 & 22 \\
\hline 3 & $\mathrm{Au}_{25} / \mathrm{Zn}_{0.33} \mathrm{MgAl}-400$ & 0.763 & 0.153 & 0.306 & 2.289 & 9 & 22 \\
\hline 4 & $\mathrm{Au}_{25} / \mathrm{Zn}_{3} \mathrm{MgAl}-400$ & 0.760 & 0.153 & 0.306 & 2.280 & 17 & 31 \\
\hline 5 & $\mathrm{Au}_{25} / \mathrm{ZnAl}-400$ & 0.755 & 0.154 & 0.308 & 2.265 & 33 & 30 \\
\hline
\end{tabular}

a: Lattice parameter: $a=2 \mathrm{~d}_{110}{ }^{\mathrm{b}}$ : Lattice parameter: $c=3 \mathrm{~d}_{003} .{ }^{c}$ : Average crystallite size: calculated using the Scherrer equation.

\subsection{Particle Size of Gold}

To further observe the dispersion of gold particles and examine the average particle sizes, transmission electron microscopy (TEM) was performed over the above catalysts. The TEM images and size distribution histograms are displayed in Figure 4. From the photos, the gold particles in all samples are almost highly dispersed, with average particle sizes of $2.6 \pm 0.9,1.8 \pm 0.7,1.9 \pm 0.7,1.9 \pm 0.6,1.9 \pm 0.8 \mathrm{~nm}$ for the $\mathrm{Au}_{25} / \mathrm{MgAl}-400$ (Figure 4a), $\mathrm{Au}_{25} / \mathrm{Zn}_{0.05} \mathrm{MgAl}-400$ (Figure $4 \mathrm{~b}$ ), $\mathrm{Au}_{25} / \mathrm{Zn}_{0.33} \mathrm{MgAl}-400$ (Figure $4 \mathrm{c}$ ), $\mathrm{Au}_{25} / \mathrm{Zn}_{3} \mathrm{MgAl}-400$ (Figure $4 \mathrm{~d}$ ) and $\mathrm{Au}_{25} / \mathrm{ZnAl}-400$ (Figure $4 \mathrm{e}$ ) catalysts, respectively. Obviously, the addition of $\mathrm{Zn}^{2+}$ ions greatly reduced the particle sizes of gold from $2.6 \mathrm{~nm}$ to $1.8 \mathrm{~nm}$, and facilitated the dispersion, which probably derived from the strong interaction between gold with Zn-contained carrier [30,37].
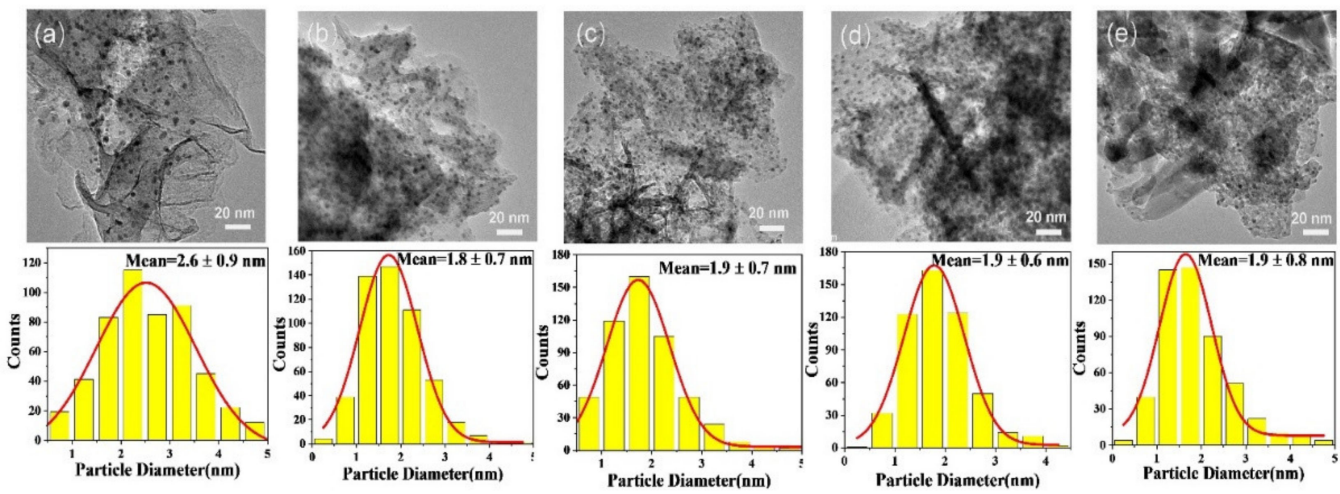

Figure 4. TEM images of $\mathrm{Zn}-\mathrm{Mg}-\mathrm{Al}$ mixed oxides-supported gold catalysts: (a) $\mathrm{Au}_{25} / \mathrm{MgAl}-400$; (b) $\mathrm{Au}_{25} / \mathrm{Zn}_{0.05} \mathrm{MgAl}-400$; (c) $\mathrm{Au}_{25} / \mathrm{Zn}_{0.33} \mathrm{MgAl}-400$; (d) $\mathrm{Au}_{25} / \mathrm{Zn}_{3} \mathrm{MgAl}-400$; (e) $\mathrm{Au}_{25} / \mathrm{ZnAl}-400$.

\subsection{Electronic Property of the Catalysts}

To study the chemical state of elements in different samples, X-ray photoelectron spectroscopy (XPS) was performed on C1s, O1s, Au 4f, Zn 3p and Mg 2s, as shown in Figures S2 and S3, and Figure 5. The binding energy of each element was calibrated by referencing them to the energy of the $\mathrm{C} 1$ s peak at $284.6 \mathrm{eV}$ (Figure S2). All catalysts showed distinguished peaks around at $83.3 \mathrm{eV}$ and $87.0 \mathrm{eV}$, respectively, which could be assigned to the $\mathrm{Au} 4 \mathrm{f} 7 / 2$ and $\mathrm{Au} 4 \mathrm{f} 5 / 2$ lines of metallic Au (Figure 5) [38]. The peak located at $88.2 / 88.3 \mathrm{eV}$ is assigned to the peaks of $\mathrm{Mg} 2 \mathrm{~s}$ and/or $\mathrm{Zn} \mathrm{3p}$, which is identified by the purple and blue bands. Obviously, with the increase in $\mathrm{Zn}^{2+}$ ions, the intensity of peaks ascribed to $\mathrm{Zn} 3 \mathrm{p}$ increase, but the peaks of $\mathrm{Mg} 2 \mathrm{~s}$ decrease correspondingly. Of note, a slight shift to low binding energy of Au was observed over the $\mathrm{Au}_{25} / \mathrm{Zn}_{0.05} \mathrm{MgAl}-400$ (83.2 eV, Figure 5b), $\mathrm{Au}_{25} / \mathrm{Zn}_{0.33} \mathrm{MgAl}-400$ (83.1 eV, Figure 5c), $\mathrm{Au}_{25} / \mathrm{Zn}_{3} \mathrm{MgAl}-400$ (82.9 eV, 
Figure 5d) and $\mathrm{Au}_{25} / \mathrm{ZnAl}-400(83.1 \mathrm{eV}$, Figure 5e) catalysts, indicating there might be a strong interaction between gold with $\mathrm{Zn}$-contained carrier. This was consistent with the results of TEM, which shows the reduction of sizes originated from the interaction of gold with the Zn-contained carrier. The O 1s XPS spectra of different gold catalysts are presented in Figure S3, which shows two peaks. One peak located at 529.7 530.2 eV was attributed to the lattice oxygen connected with $\mathrm{Mg}^{2+}$ and/or $\mathrm{Zn}^{2+}$ [39], whereas the other peak located at $531.3 \sim 531.6 \mathrm{eV}$ was assigned to hydroxide and adsorbed water $[39,40]$, which originated from the interlaminar anions of hydrotalcites.
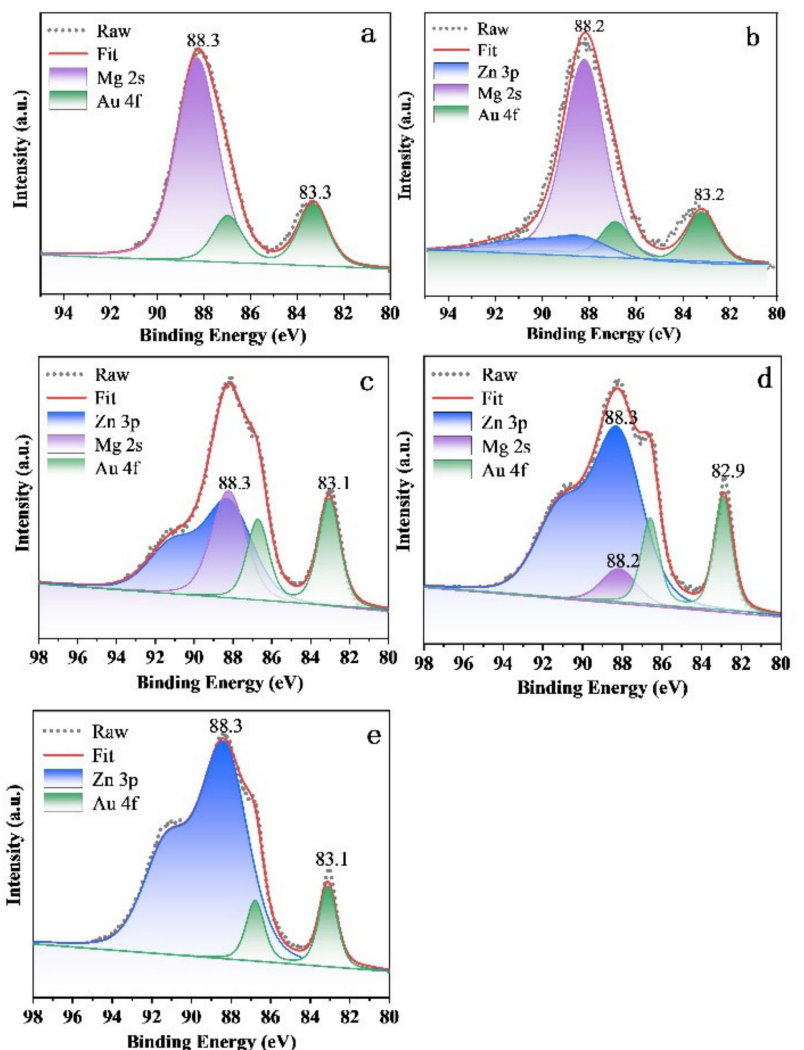

Figure 5. XPS Spectra of $\mathrm{Au} 4 \mathrm{f}-\mathrm{Zn} 3 \mathrm{p}-\mathrm{Mg}$ 2s of $\mathrm{Zn}-\mathrm{Mg}-\mathrm{Al}$ oxides-supported gold catalysts: (a) $\mathrm{Au}_{25} / \mathrm{MgAl}-400$; (b) $\mathrm{Au}_{25} / \mathrm{Zn}_{0.05} \mathrm{MgAl}-400$; (c) $\mathrm{Au}_{25} / \mathrm{Zn}_{0.33} \mathrm{MgAl}-400$; (d) $\mathrm{Au}_{25} / \mathrm{Zn}_{3} \mathrm{MgAl}-400$; (e) $\mathrm{Au}_{25} / \mathrm{ZnAl}-400$

\subsection{Basicity of the Catalysts}

$\mathrm{Mg}$-Al hydrotalcite or its derived oxide is a well-known solid base, which is widely used as a catalyst or support [19-22]. In the literature, the basicity of the catalyst was reported to facilitate the oxidative esterification of aldols [41,42]. Our group also reported that the strong basic sites benefit the formation of hemiacetal intermediate, which contributes to the synthesis of the final product [31]. Hence, in this work, $\mathrm{CO}_{2}-\mathrm{TPD}$ was utilized to determine the intensity of basic sites of $\mathrm{Zn}-\mathrm{Mg}$ - $\mathrm{Al}$ mixed oxides-supported gold catalysts. The amounts of basic sites were quantitatively measured by $\mathrm{CO}_{2}$-pulseadsorption experiments. The results are summarized in Table 1 . It is clear that the basicity of catalysts sharply decreased from $158 \mu \mathrm{mol} \cdot \mathrm{g}^{-1}$ to $23 \mu \mathrm{mol} \cdot \mathrm{g}^{-1}$ with the increase in $\mathrm{Zn}^{2+}$ ions. This implies the basicity of catalysts mainly derived from the $\mathrm{MgO}$ phase in the composite oxides [21]. Furthermore, according to the desorption temperature of carbon dioxide, the basic sites could be roughly classified into four types, namely, weak basic sites $\left(<250{ }^{\circ} \mathrm{C}\right)$, medium basic sites $\left(250-400{ }^{\circ} \mathrm{C}\right)$, strong basic sites $\left(400-620^{\circ} \mathrm{C}\right)$ and super strong basic sites $\left(>620^{\circ} \mathrm{C}\right)[41,43]$. Generally, the weak basic sites were caused by hydroxide groups [44]. The medium basic sites were attributed to $\mathrm{M}^{2+}-\mathrm{O}^{2-}$ pairs and the strong basic sites were assigned to lattice oxygen [44]. As displayed in Figure 6, the amounts of weak 
basic sites increased with the increase of $\mathrm{Zn}$, but the medium basic sites and strong basic sites reduced accordingly.

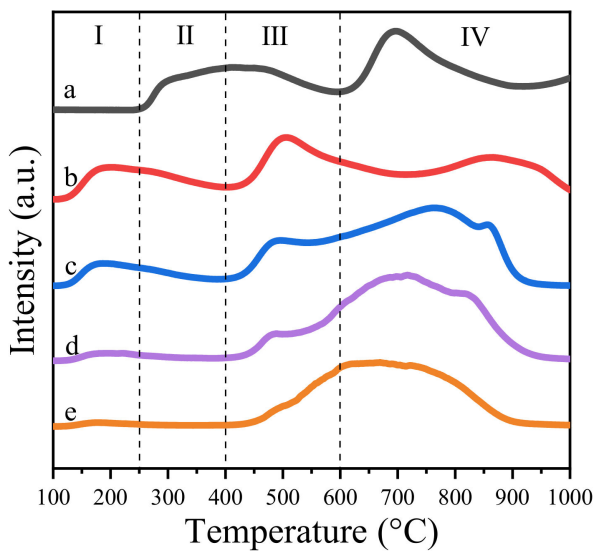

Figure 6. $\mathrm{CO}_{2}$-TPD profiles of $\mathrm{Zn}-\mathrm{Mg}$-Al mixed oxides-supported gold catalysts: (a) $\mathrm{Au}_{25} / \mathrm{MgAl}-400$; (b) $\mathrm{Au}_{25} / \mathrm{Zn}_{0.05} \mathrm{MgAl}-400$; (c) $\mathrm{Au}_{25} / \mathrm{Zn}_{0.33} \mathrm{MgAl}-400$; (d) $\mathrm{Au}_{25} / \mathrm{Zn}_{3} \mathrm{MgAl}-400$; (e) $\mathrm{Au}_{25} / \mathrm{ZnAl}-400$.

\subsection{Catalytic Performances}

The catalytic performances of above $\mathrm{Zn}-\mathrm{Mg}$-Al mixed oxides-supported gold catalysts were investigated in direct oxidative esterification of isobutyraldehyde with methanol for synthesis of methyl isobutyrate (Scheme 1). The results are displayed in Table 3 and Figure S4. From the results, the $\mathrm{Au}_{25} / \mathrm{MgAl}-400$ catalyst showed good performance with conversion of $78.5 \%$ and selectivity of $96.8 \%$ (Table 3, entry 1 ). When $5 \%$ of $\mathrm{Zn}^{2+}$ ions were added into the $\mathrm{Mg}$-Al binary system, the conversion of isobutyraldehyde increased to $88.6 \%$, with the selectivity of $96.6 \%$. Meanwhile, the turnover frequency (TOF) of gold catalysts increased from 1499 to $1933 \mathrm{~h}^{-1}$ (Table 3, entry 2), suggesting that the catalytic performance could be well improved by the addition of $\mathrm{Zn}$. However, further increase in the content of $\mathrm{Zn}^{2+}$ ions would not enhance the catalytic performances. On the contrary, the activity and selectivity would reduce consecutively. For example, over the $\mathrm{Au}_{25} / \mathrm{Zn}_{0.33} \mathrm{MgAl}-400$ catalyst, the conversion and selectivity are $68.0 \%$ and $95.9 \%$, respectively. Over the $\mathrm{Au}_{25} / \mathrm{Zn}_{3} \mathrm{MgAl}-400$ catalyst, the conversion and selectivity decreased to $65.2 \%$ and $95.0 \%$. On the $\mathrm{Au}_{25} / \mathrm{ZnAl}-400$ catalyst, the conversion reduced to $59.0 \%$ and the selectivity decreased to $93.0 \%$. This meant the optimum addition amount of $\mathrm{Zn}$ follows the volcanic curve, and only small amount of $\mathrm{Zn}$ promotes the catalytic reactivity. To further affirm the result, we also performed the reaction under the same conditions three times and plotted the histogram with error bar, as displayed in Figure 7. It is clear that the $\mathrm{Au}_{25} / \mathrm{Zn}_{0.05} \mathrm{MgAl}-400$ catalyst indeed shows the best performance.

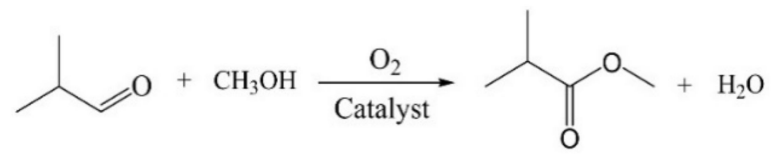

Scheme 1. Reaction pathway of isobutyraldehyde with $\mathrm{MeOH}$ to form methyl isobutyrate.

To further study the evolution of product distributions during the reaction process, dynamic experiments were conducted over the $\mathrm{Au}_{25} / \mathrm{Zn}_{\mathrm{x}} \mathrm{MgAl}-400$ catalysts. The yields of methyl isobutyrate and by-products of acetal and isobutyric acid with reaction time are plotted in Figure S4. From the curves, the trends on product distributions over different catalysts were somewhat different. In the process of reaction, methyl isobutyrate was formed as the sacrifice of isobutyraldehyde. At the same time, acetal, isobutyric acid and other ester compounds appeared as the by-products. Of note, the content of acetal and isobutyric acid are more with the $\mathrm{Au}_{25} / \mathrm{ZnAl}-400$ catalyst than the others, implying the 
transformation of isobutyraldehyde to its final target product is harder on the $\mathrm{Au}_{25} / \mathrm{ZnAl}-$ 400 catalyst than that of the $\mathrm{Au}_{25} / \mathrm{Zn}_{\mathrm{x}} \mathrm{MgAl}-400$ catalysts.

Table 3. Catalytic performances of $\mathrm{Zn}-\mathrm{Mg}-\mathrm{Al}$ mixed oxides-supported gold catalysts for synthesis of methyl isobutyrate from isobutyraldehyde and methanol.

\begin{tabular}{|c|c|c|c|c|c|c|c|}
\hline \multirow[b]{2}{*}{ Entry } & \multirow[b]{2}{*}{ Catalysts } & \multirow[b]{2}{*}{ Conversion $\%^{a}$} & \multicolumn{4}{|c|}{ Selectivity $\%{ }^{a}$} & \multirow{2}{*}{$\begin{array}{r}\text { TOF } \\
\left(h^{-1}\right)\end{array}$} \\
\hline & & & $\begin{array}{c}\text { Methyl } \\
\text { Isobutyrate }\end{array}$ & $\begin{array}{c}\text { Isobutyric } \\
\text { Acid }\end{array}$ & Acetal & Others & \\
\hline 1 & $\mathrm{Au}_{25} / \mathrm{MgAl}-400$ & 78.5 & 96.8 & 0.54 & 0.27 & 2.43 & 1499 \\
\hline 2 & $\mathrm{Au}_{25} / \mathrm{Zn}_{0.05} \mathrm{MgAl}-400$ & 88.6 & 96.6 & 0.73 & 0.20 & 2.45 & 1933 \\
\hline 3 & $\mathrm{Au}_{25} / \mathrm{Zn}_{0.33} \mathrm{MgAl}-400$ & 68.0 & 95.9 & 0.29 & 0.49 & 3.32 & 1790 \\
\hline 4 & $\mathrm{Au}_{25} / \mathrm{Zn}_{3} \mathrm{MgAl}-400$ & 65.2 & 95.0 & 0.38 & 0.74 & 3.93 & 1713 \\
\hline 5 & $\mathrm{Au}_{25} / \mathrm{ZnAl}-400$ & 59.0 & 93.0 & 0.23 & 1.28 & 5.48 & 1252 \\
\hline 6 & $\mathrm{Au}_{25} / \mathrm{Zn}_{0.05} \mathrm{MgAl}-400^{\mathrm{b}}$ & 2.12 & Trace & - & - & - & - \\
\hline 7 & $\mathrm{Zn}_{0.05} \mathrm{MgAl}-400$ & 5.26 & Trace & - & - & - & - \\
\hline
\end{tabular}

Reaction conditions: Amounts of catalyst: $40 \mathrm{mg}$; isobutyl aldehyde: $5 \mathrm{mmol}$; methanol: $5 \mathrm{~mL}$; o-xylene (interior standard): $1 \mathrm{mmol}$; reaction temperature: $80^{\circ} \mathrm{C}$; pressure of $\mathrm{O}_{2}: 4 \mathrm{~atm}$; reaction time: $2 \mathrm{~h}$. ${ }^{\mathrm{a}}$ : Conversion and selectivity were calculated by the results of gas chromatography; ${ }^{b}: \mathrm{O}_{2}$ was replaced by $\mathrm{N}_{2}(4 \mathrm{~atm}){ }^{c}$ : TOF was calculated by moles of converted aldehyde per mole of gold per hour, the reaction rate was calculated below $20 \%$ conversion.

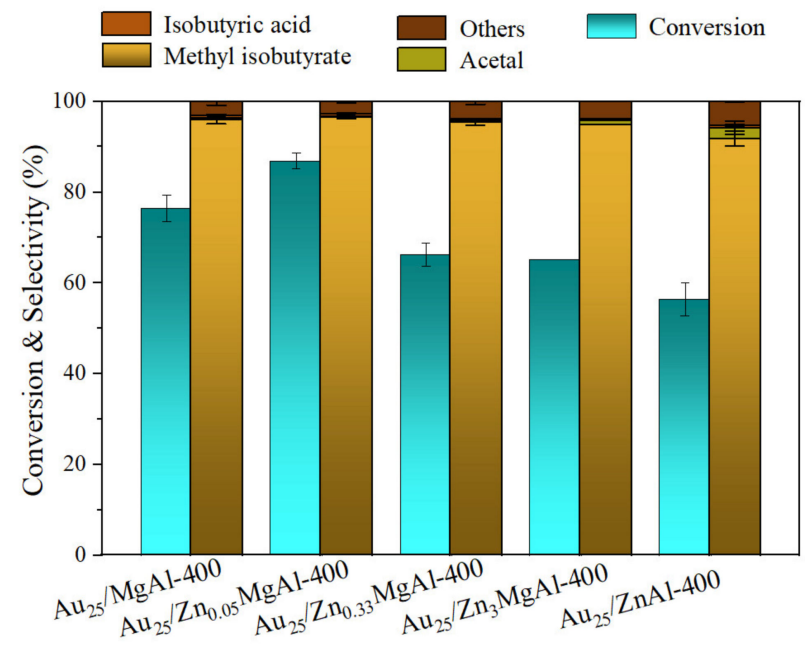

Figure 7. Catalytic performances of $\mathrm{Zn}-\mathrm{Mg}$-Al mixed oxides-supported gold catalysts for synthesis of methyl isobutyrate with error bar. Reaction conditions: catalyst: $40 \mathrm{mg}$; isobutyl aldehyde: $5 \mathrm{mmol}$; methanol: $5 \mathrm{~mL}$; reaction temperature: $80{ }^{\circ} \mathrm{C}$; pressure of $\mathrm{O}_{2}: 4 \mathrm{~atm}$; reaction time: $2 \mathrm{~h}$.

\section{Discussion}

According to our previous characterizations, the small amounts of $\mathrm{Zn}^{2+}$ ions ( $\left.\sim \mathrm{wt} . \%\right)$ would lead to the reduction of gold particle size to below $2 \mathrm{~nm}$ (Figure 4 ) and enhance the interaction between gold with the support (Figure 5). Hence, we have a reason to believe that the improved activity is connected with the decreased sizes ascribed to the addition of $\mathrm{Zn}$. In fact, many investigations have demonstrated that the activity of gold catalyst is markedly dependent on the particle size [45,46], since small gold particles possess more coordinated-unsaturated gold species, which supply more adsorption sites for reactants [46]. However, based on the results of catalytic performances, further increasing the content of $\mathrm{Zn}^{2+}$ ions would decrease the activity, even though the particle size of gold is still below $2 \mathrm{~nm}$. Thus, this strongly suggests the size of gold was not the only factor that influences the catalytic performance.

Previously, we have proposed that the basicity of catalysts is critical for oxidative esterification [31]. Various works also suggest that the basic sites can accelerate the formation of hemiacetal intermediate, thus contributing to the formation of target esters $[47,48]$. To examine the basic sites of our catalysts, $\mathrm{CO}_{2}$-TPD experiments were then carried out on the 
above catalysts. From the results, it is clear to see the total basicity of catalysts decreased gradually with the increase of $\mathrm{Zn}^{2+}$ ions (Table 1). Meanwhile, the intensity of strong basic sites decreased correspondingly (Figure 6). Based on the previous literature, the strong basic sites are proposed to be the key sites for enhancement of the intermediate [47,49]. Thus, with the decrease of intensity assigned to strong basic sites, the catalytic performances would be decreased. This is consistent with our result. Therefore, the activity of $\mathrm{Zn}-\mathrm{Mg}-\mathrm{Al}$ mixed oxides-supported gold catalysts were supposed to be sectionally influenced by the particle size of gold and the basicity of supports.

Furthermore, to clarify the effect of loading gold particles, comparison experiments were conducted on $\mathrm{Zn}_{0.05} \mathrm{MgAl}-400$ catalyst or with $\mathrm{N}_{2}$ as the source gas (Table 3, entry 7, 6). Both situations give no products after reaction under the same conditions, suggesting that the gold particles were the critical components for oxidative esterification. Our previous work demonstrated that a calcination temperature above $300^{\circ} \mathrm{C}$ was sufficient to remove most of the protective ligands [30], so that bare gold particles could be exposed on the surface of catalyst. Besides, it has been reported that the gold clusters below $2 \mathrm{~nm}$ could be active for dissociation of the molecular oxygen [50,51]. Hence, with respect to this work, we speculate that the role of gold is probably activating and dissociating oxygen so the oxidative esterification could be progressed successfully.

Considering the effect of basic sites for transformation of isobutyl aldehyde and the large role of dissociation of oxygen on the gold particles, the active center is believed to be located at the interface between metallic gold with the support. Therefore, the reaction mechanism over the above catalysts could be proposed based on the results and the literature [31,49,52]. That is, oxygen was dissociated into the adsorbed atoms on gold particles and reacts with methanol to form methoxy groups [46,50]. Then, the isobutyl aldehyde molecules were oxidized by atomic oxygen to form isobutyric acid or underwent nucleophilic attack by methoxy groups to form the surface hemiacetal intermediate. Later, during the oxidation of intermediate hemiacetal, the hemiacetal transforms to the target ester via $\beta-\mathrm{H}$ elimination with the assistant of atomic oxygen or forms the acetal by-product by reacting with methoxy groups.

\section{Materials and Methods}

\subsection{Materials}

Sodium hydroxide $(\mathrm{NaOH}, \mathrm{AR})$, sodium carbonate $\left(\mathrm{Na}_{2} \mathrm{CO}_{3}, \mathrm{AR}\right)$, hydrogen tetrachloroaurate hydrate $\left(\mathrm{HAuCl}_{4} \cdot 3 \mathrm{H}_{2} \mathrm{O}\right)$, methanol $(\mathrm{AR})$ and aluminum nitrate hydrate $\left.\left(\mathrm{Al}\left(\mathrm{NO}_{3}\right)_{3} \cdot 9 \mathrm{H}_{2} \mathrm{O}\right), 99 \%\right)$ were purchased from Sinopharm. Sodium borohydride $\left(\mathrm{NaBH}_{4}\right.$, $97 \%$ ) and magnesium nitrate hexahydrate $\left.\left(\mathrm{Mg}\left(\mathrm{NO}_{3}\right)_{3} \cdot 6 \mathrm{H}_{2} \mathrm{O}\right), 99 \%\right)$ were purchased from Shanghai Lingfeng Chemical Reagent Company. Isobutyl aldehyde (98\%), cysteine (99\%), methyl isobutyrate $(99 \%)$, ortho-xylene $(\mathrm{CP})$ and zinc nitrate hydrate $\left(\mathrm{Zn}\left(\mathrm{NO}_{3}\right)_{2} \cdot 6 \mathrm{H}_{2} \mathrm{O}\right)$, 99\%) were purchased from Aladdin Industrial Corporation. All chemicals were used directly without any purification. All glassware was washed with Aqua Regia and rinsed with ethanol and ultrapure water $(18.2 \mathrm{M} \Omega)$.

\subsection{Catalyst Preparation}

The $\mathrm{Zn}-\mathrm{Mg}$-Al hydrotalcites (HTs) with different $\mathrm{Zn}^{2+} / \mathrm{Mg}^{2+}$ molar ratios were prepared by a co-precipitation method. Typically, specific amounts of $\mathrm{Zn}\left(\mathrm{NO}_{3}\right)_{2} \cdot 6 \mathrm{H}_{2} \mathrm{O}(0$, $0.03,0.2,0.42,0.63 \mathrm{~mol}), \mathrm{Mg}\left(\mathrm{NO}_{3}\right)_{2} \cdot 6 \mathrm{H}_{2} \mathrm{O}(0.63,0.6,0.42,0.2,0 \mathrm{~mol})$ and $\mathrm{Al}\left(\mathrm{NO}_{3}\right)_{3} \cdot 9 \mathrm{H}_{2} \mathrm{O}$ $(0.21 \mathrm{~mol}$ ) were mixed with $200 \mathrm{~mL}$ of ultrapure water to obtain a solution (denoted as solution A). $\mathrm{Na}_{2} \mathrm{CO}_{3}(0.113 \mathrm{~mol})$ and $\mathrm{NaOH}(0.438 \mathrm{~mol})$ were mixed with $200 \mathrm{~mL}$ of ultrapure water in a $500 \mathrm{~mL}$ round-bottom flask to obtain solution $\mathrm{B}$. Under vigorous stirring in a water bath at $70{ }^{\circ} \mathrm{C}$, solution A was pumped into solution B very slowly. Then, the obtained mixture was aged at $70^{\circ} \mathrm{C}$ for about $24 \mathrm{~h}$ with constant stirring. Following filtering, washing and drying overnight, the $\mathrm{Zn}-\mathrm{Mg}$-Al HTs were obtained, which were denoted as MgAl-HT; $\mathrm{Zn}_{0.05} \mathrm{MgAl}-\mathrm{HT} ; \mathrm{Zn}_{0.33} \mathrm{MgAl}-\mathrm{HT} ; \mathrm{Zn}_{3} \mathrm{MgAl}-\mathrm{HT}$ and $\mathrm{ZnAl}-\mathrm{HT}$ (0.05, 0.33 and 3 denote the molar ratio of $\mathrm{Zn}^{2+} / \mathrm{Mg}^{2+}$ ). 
Zn-Mg-Al mixed oxides-supported gold catalysts were prepared as follows. Firstly, gold clusters protected by thiolate-ligands (cysteine) were prepared by a $\mathrm{NaBH}_{4}$ reduction method according to our previous work [30]. Typically, $1.485 \mathrm{~mL}$ of $\mathrm{HAuCl}_{4}\left(19.12 \mathrm{~g}_{\mathrm{Au}} / \mathrm{L}\right)$ was dissolved in $25 \mathrm{~mL}$ of ultrapure water under vigorous stirring for $5 \mathrm{~min}$. Then, $37.5 \mathrm{~mL}$ of cysteine solution $(5.61 \mathrm{mM})$ and $7.5 \mathrm{~mL}$ of $1 \mathrm{M} \mathrm{NaOH}$ solution were successively added into the solution. After about $1 \mathrm{~h}$, excessive and fresh prepared $\mathrm{NaBH}_{4}$ solution was poured into the solution quickly and we continued to stir for $3 \mathrm{~h}$. UV-Vis spectra were analyzed to define the products as $\mathrm{Au}_{25}$ nanoclusters. Then, about $2.5 \mathrm{~g}$ of powder of support was added into the aqueous solution of $\mathrm{Au}_{25}$ clusters. Then, $2 \mathrm{~h}$ later, the resulting mixture was filtered, washed and dried to obtain the precursor of the catalyst. Before catalytic testing, the precursors of the catalysts were calcined at $400{ }^{\circ} \mathrm{C}$ for $120 \mathrm{~min}$, which were denoted as $\mathrm{Au}_{25} / \mathrm{MgAl}-400 ; \mathrm{Au}_{25} / \mathrm{Zn}_{0.05} \mathrm{MgAl}-400 ; \mathrm{Au}_{25} / \mathrm{Zn}_{0.33} \mathrm{MgAl}-400 ; \mathrm{Au}_{25} / \mathrm{Zn}_{3} \mathrm{MgAl}-400$ and $\mathrm{Au}_{25} / \mathrm{ZnAl}-400$.

\subsection{Catalyst Characterization}

The actual loadings of gold in all of the catalysts were determined by inductively coupled plasma atomic emission spectroscopy (ICP-AES) on an IRIS Intrepid II XSP instrument (Thermo Electron Corporation, Waltham, Massachusetts, USA). UV-Vis absorption spectroscopy (EVO300, Waltham, Massachusetts, USA) was utilized to precisely define the atomic $\mathrm{Au}_{25}$ nanoclusters, with water as the reference. The X-ray diffraction (XRD) analysis was conducted on a PW3040/60 X'Pert PRO (PANalytical, Almelo, The Netherlands) diffractometer, with a $\mathrm{Cu} K \alpha$ radiation source $(\lambda=0.15432 \mathrm{~nm})$ in a scanning angle

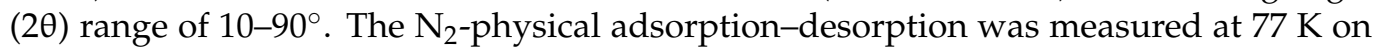
a Quantachrome NT3LX-2 instrument after degassing the samples at $300^{\circ} \mathrm{C}$ for $120 \mathrm{~min}$. The pore size distribution and the specific surface area were calculated by the $\mathrm{BJH}$ and BET methods. The high-resolution transmission electron microscopy (HRTEM) and TEM were recorded on a JEM-2100F microscope at $200 \mathrm{kV}$. The X-ray photoelectron spectra (XPS) were conducted on an ESCLALAB 250Xi X-ray photoelectron spectrometer equipped with a monochromatic $\mathrm{Al}$ and double anode $\mathrm{Al} / \mathrm{Mg}$ target. The binding energy was calibrated using the $\mathrm{C} 1 \mathrm{~s}$ peak $(284.6 \mathrm{eV})$ as the reference. The temperature-programmed desorption of carbon dioxide ( $\mathrm{CO}_{2}$-TPD) experiments was studied on a Micromeritics Autochem II 2920 chemisorber equipped with a thermal conductivity detector and mass spectrometry. Firstly, about $100 \mathrm{mg}$ of the catalysts was pretreated in a U-type quartz tube reactor with a He gas stream $\left(50 \mathrm{~cm}^{3} / \mathrm{min}\right)$ at $400{ }^{\circ} \mathrm{C}$ for $30 \mathrm{~min}$. After the temperature decreased to $100{ }^{\circ} \mathrm{C}$, the catalysts were saturated with $10 \% \mathrm{CO}_{2} / \mathrm{He}$ flow $\left(30 \mathrm{~cm}^{3} / \mathrm{min}\right)$ for $15 \mathrm{~min}$. Then, the samples were purged in helium at $100^{\circ} \mathrm{C}$ for $30 \mathrm{~min}$ and waited for baseline balance. Finally, the $\mathrm{CO}_{2}$-TPD profile of the sample was recorded by increasing the temperature from $100{ }^{\circ} \mathrm{C}$ to $1000{ }^{\circ} \mathrm{C}$ at a heating rate of $10^{\circ} \mathrm{C} / \mathrm{min}$ under He flow.

\subsection{Catalytic Test}

Catalytic evaluation of one step oxidative esterification for synthesis of methyl isobutyrate from isobutyraldehyde and methanol was carried out in stainless steel autoclave equipped with magnetic stirring and pressure gauge. Typically, certain amounts of catalysts and the mixture of isobutyraldehyde $(1 \mathrm{M})$ and methanol $(5 \mathrm{~mL})$ were introduced into the reactor. After sealing, the air in the autoclave was replaced with oxygen six times and then pressurized to $4 \mathrm{~atm}$. Before the reaction, the reactants were gradually heated to $353 \mathrm{~K}$ in a water bath and initiated to stir. When the reaction finished, the reactor was placed in an ice bath immediately to terminate the reaction. The products were identified by GC-MS (Agilent 5977B MSD GC/MS) and analyzed quantitatively by GC (Agilent 7890 A) with a flame ionization detector (FID) and a HP-5 column ( $30 \mathrm{~m}, 0.25 \mathrm{~mm}$ inner diameter).

\section{Conclusions}

A series of $\mathrm{Zn}-\mathrm{Mg}$-Al hydrotalcites and derived mixed oxides-supported gold catalysts with different $\mathrm{Zn}^{2+} / \mathrm{Mg}^{2+}$ molar ratios were prepared for one-step oxidative esterification 
of isobutyraldehyde with methanol to form methyl isobutyrate. Adding a small amount of $\mathrm{Zn}^{2+}$ ions ( $\left.\sim \mathrm{wt} . \%\right)$ provoked a remarkable modification of catalytic performance for the binary $\mathrm{Mg}-\mathrm{Al}$ system, which enhanced the activity of catalysts from $78.5 \%$ to $88.6 \%$ and TOF values from $1499 \mathrm{~h}^{-1}$ to $1933 \mathrm{~h}^{-1}$. Characterizations of structure and electronic properties demonstrated the addition of $\mathrm{Zn}$ not only reduced the particle size of gold but also enhanced the interaction between gold with the support. Furthermore, the catalytic performance was also highly dependent on the basicity of the catalyst. Based on a comparison experiment, the active center was believed to be located at the interface between metallic gold with the support, in which basicity plays a big role in transformation of the intermediates. This work provides deep insights into one-step oxidation esterification of aldehydes and alcohols over ternary system and supported gold catalysts.

Supplementary Materials: The following are available online at https:/ / www.mdpi.com/article/10 .3390/ijms22168668/s1.

Author Contributions: Y.T. and Y.D. conceived the study; J.L. performed most of the experiments; S.W. and H.L. contributed to the characterizations. All authors contributed to the writing of the manuscript. All authors have read and agreed to the published version of the manuscript.

Funding: This research was funded by Zhejiang Provincial Natural Science Foundation of China under Grant No. LQ20B030005.

Institutional Review Board Statement: Not applicable.

Informed Consent Statement: Not applicable.

Data Availability Statement: Data is available upon request from the corresponding authors.

Acknowledgments: The authors would like to thank the public testing platform of Zhejiang Normal University and Dalian Institute of Chemical Physics, Chinese Academy of Sciences.

Conflicts of Interest: The authors declare no conflict of interest.

\section{References}

1. Ray, R.; Jana, R.D.; Bhadra, M.; Maiti, D.; Lahiri, G.K. Efficient and Simple Approaches Towards Direct Oxidative Esterification of Alcohols. Chem. Eur. J. 2014, 20, 15618-15624. [CrossRef]

2. Hou, F.; Wang, X.-C.; Quan, Z.-J. Efficient synthesis of esters through oxone-catalyzed dehydrogenation of carboxylic acids and alcohols. Org. Biomol. Chem. 2018, 16, 9472-9476. [CrossRef] [PubMed]

3. Jayachitra, G.; Yasmeen, N.; Rao, K.S.; Ralte, S.L.; Srinivasan, R.; Singh, A.K. Synthetic Communications: An International Journal for Rapid Communication of Synthetic Organic Chemistry. Synth. Commun. 2003, 33, 3461-3466.

4. Gaspa, S.; Porcheddu, A.; Luca, L.D. Metal-Free Oxidative Cross Esterification of Alcohols via Acyl Chloride Formation. Adv. Synth. Catal. 2016, 358, 154-158. [CrossRef]

5. Abiko, A.; Roberts, J.C.; Takemasa, T.; Masamune, S. $\mathrm{KMnO}_{4}$ revisited: Oxidation of aldehydes to carboxylic acids in the-butyl alcohol-aqueous $\mathrm{NaH}_{2} \mathrm{PO}_{4}$ system. Tetrahedron Lett. 1986, 27, 4537-4540. [CrossRef]

6. O'Connor, B.; Just, G. ChemInform Abstract: A New Method for the Conversion of Aldehydes to Methyl Esters Using Pyridinium Dichromate and Methanol in Dimethylformamide. Tetrahedron Lett. 1987, 28, 3235-3236. [CrossRef]

7. Wu, X.F. Zinc-catalyzed oxidative esterification of aromatic aldehydes. Tetrahedron Lett. 2012, 53, 3397-3399. [CrossRef]

8. Powell, A.B.; Stahl, S.S. Aerobic Oxidation of Diverse Primary Alcohols to Methyl Esters with a Readily Accessible Heterogeneous $\mathrm{Pd} / \mathrm{Bi} / \mathrm{Te}$ Catalyst. Org. Lett. 2013, 15, 5072-5075. [CrossRef]

9. Liu, C.; Tang, S.; Zheng, L.; Liu, D.; Zhang, H.; Lei, A. Covalently Bound Benzyl Ligand Promotes Selective Palladium Catalyzed Oxidative Esterification of Aldehydes with Alcohols. Angew. Chem. Int. Ed. 2012, 51, 5662-5666. [CrossRef]

10. Biajoli, A.F.P.; Peringer, F.; Monteiro, A.L. Pd(OAc) $)_{2} /$ dppp, an efficient catalytic system for the oxidative esterification of benzaldehyde using organic halides as oxidants. Catal. Commun. 2017, 89, 48-51. [CrossRef]

11. Mannel, D.S.; King, J.; Preger, Y.; Ahmed, M.S.; Root, T.W.; Stah, S.S. Mechanistic Insights into Aerobic Oxidative Methyl Esterification of Primary Alcohols with Heterogeneous PdBiTe Catalysts. ACS Catal. 2018, 8, 1038-1047. [CrossRef]

12. Li, F.; Li, X.L.; Li, C.; Shi, J.; Fu, Y. Aerobic oxidative esterification of 5-hydroxymethylfurfural to dimethyl furan-2, 5-dicarboxylate by using homogeneous and heterogeneous PdCoBi/C catalysts under atmospheric oxygen. Green Chem. 2018, 20, 3050-3058. [CrossRef]

13. Hui, Y.; Zhang, S.; Wang, W. Recent Progress in Catalytic Oxidative Transformations of Alcohols by Supported Gold Nanoparticles. Adv. Synth. Catal. 2019, 361, 2215-2235. [CrossRef] 
14. Du, J.; Fang, H.; Qu, H.; Zhang, J.; Duan, X.; Yuan, Y. Fabrication of supported Au-CuOx nanohybrids by reduction-oxidation strategy for efficient oxidative esterification of 5-hydroxymethyl-2-furfural into dimethyl furan-2,5-dicarboxylate. Appl. Catal. A 2018, 567, 80-89. [CrossRef]

15. Taketoshi, A.; Ishida, T.; Murayamaa, T.; Honmac, T.; Haruta, M. Oxidative esterification of aliphatic aldehydes and alcohols with ethanol over gold nanoparticle catalysts in batch and continuous flow reactors. Appl. Catal. 2019, 585, 117169. [CrossRef]

16. Zuo, C.; Tian, Y.; Zheng, Y.; Wang, L.; Fu, Z.; Jiao, T.; Wang, M.; Huang, H.; Li, Y. A sustainable oxidative esterification of thiols with alcohols by a cobalt nanocatalyst supported on doped carbon. Catal. Commun. 2019, 124, 51-55. [CrossRef]

17. Mishra, D.K.; Choa, J.K.; Yi, Y.; Lee, H.J.; Kim, Y.J. Hydroxyapatite supported gold nanocatalyst for base-free oxidative esterification of 5-hydroxymethyl-2-furfural to 2,5-furan dimethylcarboxylate with air as oxidant. J. Ind. Eng. Chem. 2019, 70, 338-345. [CrossRef]

18. Shahin, Z.; Rataboul, F.; Demessence, A. Study of the oxidative esterification of furfural catalyzed by $\mathrm{Au}_{25}(\mathrm{glutathione})_{18}$ nanocluster deposited on zirconia. Mol. Catal. 2021, 499, 111265. [CrossRef]

19. Liu, L.; Li, H.; Tan, Y.; Chen, X.; Lin, R.; Yang, W.; Huang, C.; Wang, S.; Wang, X.; Liu, X.; et al. Metal-support synergy of supported gold nanoclusters in selective oxidation of alcohols. Catalysts 2020, 10, 107. [CrossRef]

20. Hajavazzade, R.; Kargarrazi, M.; Mahjoub, A.R. Phosphotungstic Acid Supported on $\mathrm{MgAl}_{2} \mathrm{O}_{4}$ Nanoparticles as an Efficient and Reusable Nanocatalyst for Benzylic Alcohols Oxidation with Hydrogen Peroxide. J. Inorg. Organomet. Polym. Mater. 2019, 29, 1523-1532. [CrossRef]

21. Kikhtyanin, O.; Tišler, Z.; Velvarská, R.; Kubicka, D. Reconstructed Mg-Al hydrotalcites prepared by using different rehydration and drying time: Physico-chemical properties and catalytic performance in aldol condensation. Appl. Catal. A 2017, 536, 85-96. [CrossRef]

22. Zheng, L.; Xia, S.; Hou, Z.; Zhang, M.; Hou, Z. Transesterification of glycerol with dimethyl carbonate over Mg-Al hydrotalcites. Chin. J. Catal. 2014, 35, 310-318. [CrossRef]

23. Benito, P.; Vaccari, A.; Antonetti, C.; Licursi, D.; Schiarioli, N.; Rodriguez-Castellón, E.; Galletti, A.M.R. Tunable copperhydrotalcite derived mixed oxides for sustainable ethanol condensation to n-butanol in liquid phase. J. Clean. Prod. 2019, 209, 1614-1623. [CrossRef]

24. Barrett, J.A.; Jones, Z.R.; Stickelmaier, C.; Schopp, N.; Ford, P.C. A Pinch of Salt Improves n-Butanol Selectivity in the Guerbet Condensation of Ethanol over Cu-Doped Mg/Al Oxides. ACS Sustain. Chem. Eng. 2018, 6, 15119-15126. [CrossRef]

25. Hernández, W.Y.; Aliç, F.; Verberckmoes, A.; Van Der Voort, P. Tuning the acidic-basic properties by Zn substitution in Mg-Al hydrotalcites as optimal catalysts for the aldol condensation reaction. J. Mater. Sci. 2016, 52, 628-642. [CrossRef]

26. Cheng, W.; Wang, W.; Zhao, Y.; Liu, L.; Yang, J.; He, M. Influence of acid-base properties of ZnMgAl-mixed oxides for the synthesis of 1-methoxy-2-propanol. Appl. Clay Sci. 2008, 42, 111-115. [CrossRef]

27. Wu, Y.J.; Li, P.; Yu, J.G.; Cunha, A.F.; Rodrigues, A.E. Sorption-enhanced steam reforming of ethanol on NiMgAl multifunctional materials: Experimental and numerical investigation. Chem. Eur. J. 2013, 231, 36-48. [CrossRef]

28. Pavel, O.D.; Cojocaru, B.; Angelescu, E.; Pârvulescu, V.I. The activity of yttrium-modified Mg, Al hydrotalcites in the epoxidation of styrene with hydrogen peroxide. Appl. Catal. A 2011, 403, 83-90. [CrossRef]

29. Nowicki, J.; Lach, J.; Organek, M.; Sabura, E. Transesterification of rapeseed oil to biodiesel over Zr-dopped MgAl hydrotalcites. Appl. Catal. A 2016, 524, 17-24. [CrossRef]

30. Tan, Y.; Liu, X.Y.; Zhang, L.; Wang, A.; Li, L.; Pan, X.; Miao, S.; Haruta, M.; Wei, H.; Wang, H.; et al. ZnAl-Hydrotalcite-Supported $\mathrm{Au}_{25}$ Nanoclusters as Precatalysts for Chemoselective Hydrogenation of 3-Nitrostyrene. Angew. Chem. Int. Ed. 2017, 56, 2709-2713. [CrossRef] [PubMed]

31. Li, H.; Tan, Y.; Chen, X.; Yang, W.; Huang, C.; Li, J.; Ding, Y. Efficient Synthesis of Methyl Methacrylate by One Step Oxidative Esterification over Zn-Al-Mixed Oxides Supported Gold Nanocatalysts. Catalysts 2021, 11, 162. [CrossRef]

32. Jiang, X.; Zhang, S.; Yue, M. Copper functionalized solid base prepared by potassium modification of N-doped carbons to promote the conversion of ethanol to butanol. Microporous Mesoporous Mater. 2021, 311, 110731. [CrossRef]

33. Pavel, O.D.; Tichit, D.; Tichit, D.; Marcu, I.C. Acido-basic and catalytic properties of transition-metal containing Mg-Al hydrotalcites and their corresponding mixed oxides. Appl. Clay Sci. 2012, 61, 52-58. [CrossRef]

34. Zheng, Y.; Li, N.; Zhang, W. Preparation of nanostructured microspheres of Zn-Mg-Al layered double hydroxides with high adsorption property. Colloids Surf. A Physicochem. Eng. Asp. 2012, 415, 195-201. [CrossRef]

35. Shannon, R.D. Revised effective ionic radii and systematic studies of interatomic distances in halides and chalcogenides. Acta Cryst. 1976, 32, 751-767. [CrossRef]

36. Valente, J.S.; Tzompantzi, F.; Prince, J.; Cortez, J.G.H.; Gomez, R. Adsorption and photocatalytic degradation of phenol and 2,4 dichlorophenoxiacetic acid by Mg-Zn-Al layered double hydroxides. Appl. Catal. B 2009, 90, 330-338. [CrossRef]

37. Tan, Y.; Liu, X.; Zhang, L.; Liu, F.; Wang, A.; Zhang, T. Producing of cinnamyl alcohol from cinnamaldehyde over supported gold nanocatalyst. Chin. J. Catal. 2021, 42, 470-481. [CrossRef]

38. Zuo, C.; Tian, Y.; Zheng, Y.; Wang, L.; Fu, Z.; Jiao, T.; Wang, M.; Huang, H.; Li, Y. One step oxidative esterification of methacrolein with methanol over $\mathrm{AuCeO}_{2} / \gamma-\mathrm{Al}_{2} \mathrm{O}_{3}$ catalysts. Catal. Commun. 2019, 124, 51-55. [CrossRef]

39. Bhuvaneswari, K.; Palanisamy, G.; Pazhanivel, T.; Bharathi, G.; Nataraj, D. Photocatalytic Performance on Visible Light Induced ZnS QDs-MgAl Layered Double Hydroxides Hybrids for Methylene Blue Dye Degradation. ChemistrySelect 2018, 3, 13419-13426. [CrossRef] 
40. Das, S.; Patnaik, S.; Parida, K. Dynamic charge transfer through Fermi level equilibration in the p-CuFe ${ }_{2} \mathrm{O}_{4} / \mathrm{n}-\mathrm{NiAl} \mathrm{LDH}$ interface towards photocatalytic application. Catal. Sci. Technol. 2020, 10, 6285-6298. [CrossRef]

41. Gao, J.; Fan, G.; Yang, L.; Cao, X.; Zhang, P.; Li, F. Oxidative Esterification of Methacrolein to Methyl Methacrylate over Gold Nanoparticles on Hydroxyapatite. Chem CatChem 2017, 9, 1230-1241. [CrossRef]

42. Tian, Y.; Li, Y.; Zheng, Y.; Wang, M.; Zuo, C.; Huang, H.; Yin, D.; Fu, Z.; Tan, J.; Zhou, Z. Nano-Au/MCeOx Catalysts for the Direct Oxidative Esterification of Methylacrolein to Methyl Esters. Ind. Eng. Chem. Res. 2019, 58, 19397-19405. [CrossRef]

43. Ren, J.; Mebrahtu, C.; Palkovits, R. Ni-based catalysts supported on Mg-Al hydrotalcites with different morphologies for $\mathrm{CO}_{2}$ methanation: Exploring the effect of metal-support interaction. Catal. Sci. Technol. 2020, 10, 1902-1913. [CrossRef]

44. Dębek, R.; Radlik, M.; Motak, M.; Galvez, M.E.; Turek, W.; Costa, P.D.; Grzybek, T. Ni-containing Ce-promoted hydrotalcite derived materials as catalysts for methane reforming with carbon dioxide at low temperature-On the effect of basicity. Catal. Today 2015, 257, 59-65. [CrossRef]

45. Fang, J.; Zhang, B.; Yao, Q.; Yang, Y.; Xie, J.; Yan, N. Recent advances in the synthesis and catalytic applications of ligand-protected, atomically precise metal nanoclusters. Coord. Chem. Rev. 2016, 322, 1-29. [CrossRef]

46. Taketoshi, A.; Haruta, M. Size- and Structure-specificity in Catalysis by Gold Clusters. Chem. Lett. 2014, 43, 380-387. [CrossRef]

47. Wan, X.; Deng, W.; Zhang, Q.; Wang, Y. Magnesia-supported gold nanoparticles as efficient catalysts for oxidative esterification of aldehydes or alcohols with methanol to methyl esters. Catal. Today 2014, 233, 147-154. [CrossRef]

48. Trimpalis, A.; Giannakakis, G.; Cao, S.; Flytzani-Stephanopoulos, M. NiAu single atom alloys for the selective oxidation of methacrolein with methanol to methyl methacrylate. Catal. Today 2020, 355, 804-814. [CrossRef]

49. Li, Y.; Zheng, Y.; Wang, L.; Fu, Z. Oxidative Esterification of Methacrolein to Methyl Methacrylate over Supported Gold Catalysts Prepared by Colloid Deposition. ChemCatChem 2017, 9, 1960-1968. [CrossRef]

50. Yoon, B.; Häkkinen, H.; Landman, U. Interaction of $\mathrm{O}_{2}$ with Gold Clusters: Molecular and Dissociative Adsorption. J. Phys. Chem. A 2003, 107, 4066-4071. [CrossRef]

51. Turner, M.; Golovko, V.B.; Vaughan, O.; Abdulkin, P.; Berenguer-Murcia, A.; Tikhov, M.S.; Johnson, B.F.G.; Lambert, R.M. Selective oxidation with dioxygen by gold nanoparticle catalysts derived from 55-atom clusters. Nature 2008, 454, 981-983. [CrossRef] [PubMed]

52. Xu, B.; Liu, X.; Haubrich, J.; Friend, C.M. Vapour-phase gold-surface-mediated coupling of aldehydes with methanol. Nat. Chem. 2010, 2, 61-65. [CrossRef] [PubMed] 